Article

\title{
Energy Return on Energy Invested for Tight Gas Wells in the Appalachian Basin, United States of America
}

\section{Bryan Sell $^{1, *}$, David Murphy ${ }^{2}$ and Charles A.S. Hall ${ }^{2}$}

1 Section of Earth and Environmental Sciences, University of Geneva, Rue des Maraîchers 13, Geneva 1205, Switzerland

2 Program in Environmental Science, State University of New York - College of Environmental Science and Forestry, Syracuse, NY 13210, USA; E-Mails: djmurp03@esf.edu (D.M.); chall@esf.edu (C.H.)

* Author to whom correspondence should be addressed; E-Mail: Bryan.Sell@unige.ch; Tel.: +41-78-883-72-42; Fax: +41-22-379-32-10.

Received: 26 June 2011; in revised form: 7 July 2011 / Accepted: 5 August 2011 / Published: 20 October 2011

\begin{abstract}
The energy cost of drilling a natural gas well has never been publicly addressed in terms of the actual fuels and energy required to generate the physical materials consumed in construction. Part of the reason for this is that drilling practices are typically regarded as proprietary; hence the required information is difficult to obtain. We propose that conventional tight gas wells that have marginal production characteristics provide a baseline for energy return on energy invested (EROI) analyses. To develop an understanding of baseline energy requirements for natural gas extraction, we examined production from a mature shallow gas field composed of vertical wells in Pennsylvania and materials used in the drilling and completion of individual wells. The data were derived from state maintained databases and reports, personal experience as a production geologist, personal interviews with industry representatives, and literature sources. We examined only the "upstream" energy cost of providing gas and provide a minimal estimate of energy cost because of uncertainty about some inputs. Of the materials examined, steel and diesel fuel accounted for more than two-thirds of the energy cost for well construction. Average energy cost per foot for a tight gas well in Indiana County is 0.59 GJ per foot. Available production data for this natural gas play was used to calculate energy return on energy invested ratios (EROI) between 67:1 and 120:1, which depends mostly on the amount of materials consumed, drilling time, and highly variable production. Accounting for such
\end{abstract}


inputs as chemicals used in well treatment, materials used to construct drill bits and drill pipe, post-gathering pipeline construction, and well completion maintenance would decrease EROI by an unknown amount. This study provides energy constraints at the single-well scale for the energy requirements for drilling in geologically simple systems. The energy and monetary costs of wells from Indiana County, Pennsylvania are useful for constructing an EROI model of United States natural gas production, which suggests a peak in the EROI of gas production, has already occurred twice in the past century.

Keywords: EROI; natural gas; tight gas; Appalachian Basin; Indiana County; depletion

\section{Introduction}

Natural gas now dominates the well-derived fossil fuel production of the United States; the number of wells drilled for natural gas overtook the number of wells drilled for crude oil in 1993 and now accounts for nearly $70 \%$ of the wells drilled annually [1]. Natural gas is currently the most widely used fuel by the manufacturing industry in the United States [2]. Before natural gas rose to prominence, disturbances in the natural gas market such as the U.S. gas shortage of the 1970s and the gas oversupply of the 1980s had significant effects on national economies [3]. Similar global effects are expected to occur in the near future [4], although others tend to disagree [5] Another natural gas crisis seems likely given the unprecedented rise in U.S. natural gas well cost compared to the decrease in production per well, i.e., well costs are climbing at an exponential rate while production per well is decreasing at a linear rate. Conventional economics appears to have failed at making accurate predictions on energy resource availability [6]. Thus it becomes prudent to analyze energy resources in terms of physical constraints and requirements. This situation is more serious if we consider arguments about whether the most important fields have reached maturity and are in decline, i.e., peak gas [4].

Traditionally, discussion over whether gas reserves (and oil) are in decline rely on monetary based data [7,8] and aggregate production data from multiple fields [9-11], but typically do not address how to detect whether a particular field is in physical decline. Notable exceptions can be found with recent depletion analysis studies of individual oil fields [12-14] and for large gas fields in Europe [15] that show peak production occurring at or soon after one-half of the ultimate reserves are produced followed by increasingly high decline rates. While it is tempting to assume that the same trends apply to all natural gas fields, a similar decline analysis for U.S. natural gas apparently has yet to be performed. Knowing the decline characteristics for natural gas in a given area is essential for economic planning regardless of a peak gas scenario. However, different interpretations can be made about the same production data $[8,9]$.

We propose a different approach for detecting whether a natural gas field is declining by examining individual well decline characteristics and the requirements for exploiting natural gas at the single-well scale. This approach makes sense because the overall decline rate of a given field should be controlled by the sum of the decline rates of individual wells and the energy requirements for drilling will physically and economically constrain the life of a given field. As a first step in understanding the 
limitations of natural gas reserves, the oldest and most mature fields that contain relatively inexpensive wells, such as those found in the Appalachian Basin, should be examined.

The purpose of this research is to examine the energy requirements for drilling a natural gas well compared to the energy produced, i.e., a net energy analysis or an energy return on investment (EROI). We examine how much material and their energetic equivalents are required to drill a natural gas well in the Bradford-Venango-Elk (BVE) natural gas field in Indiana County, Pennsylvania. Material requirements and resource production are examined over time in order to detect whether technology and drilling parameters affect production. The resulting information can then be used as a constraint when considering other natural gas resources in terms of their economic viability.

There are several advantages for choosing this area for EROI analysis. First, these wells are unique because they are near or already classified as marginally productive as soon as they are drilled and thus are extremely vulnerable to being abandoned or not drilled when the market price of petroleum decreases [16]. Thus, any estimates made for these wells could be considered a baseline estimate for other, more profitable wells. Second, this heavily drilled area represents one of the largest tight gas plays in the United States (Figure 1). Pennsylvania has the largest number of marginal gas wells of any state and produces the 4th largest quantity of marginal gas in the United States after West Virginia, Oklahoma, and Texas [16]. EROI could predict the future of this important natural gas resource by stating the energy requirements for exploitation. Third, Indiana County, Pennsylvania has over 100 years of natural gas exploration history and is densely populated with vertical natural gas wells (Figure 2), most of which have similar total depths, i.e., the natural gas system of this area is relatively well constrained (Figure 3). This long history [17] could serve as a useful comparison to other gas fields and possibly provide an indication as what to expect from the total gas supply of North America and beyond.

Figure 1. Tight gas plays in the United States. The different colors represent different groups of rocks that compose the various tight gas plays of the United States. The dark brown polygon in the northeast U.S. represents the Bradford-Venango-Elk tight gas play.

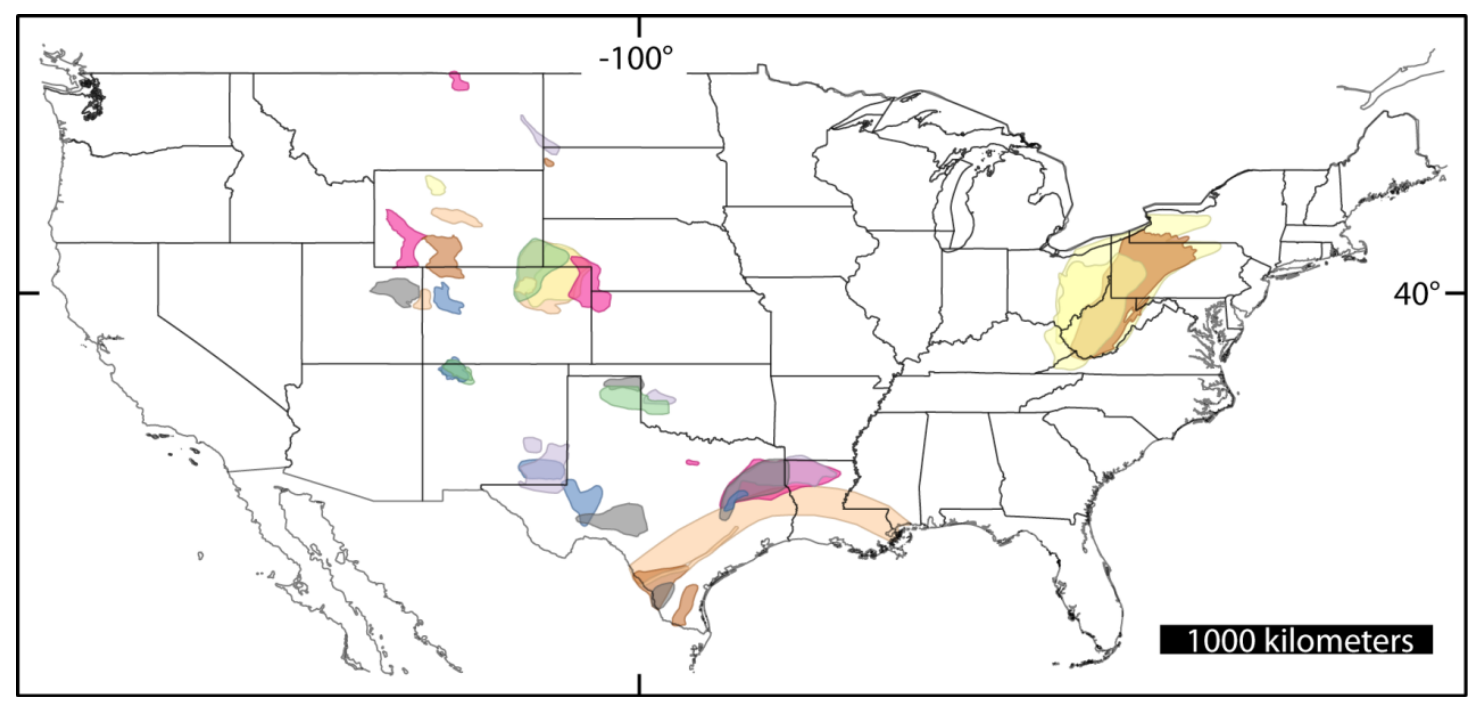


Figure 2. Map showing the Bradford-Venango-Elk (BVE) tight gas play (inset) and the distribution of all BVE wells in Indiana County, Pennsylvania, U.S. Yellow squares represent well locations examined for materials used. Red squares represent all wells that have available production records. The black squares represent all wells BVE play wells drilled in Indiana County.

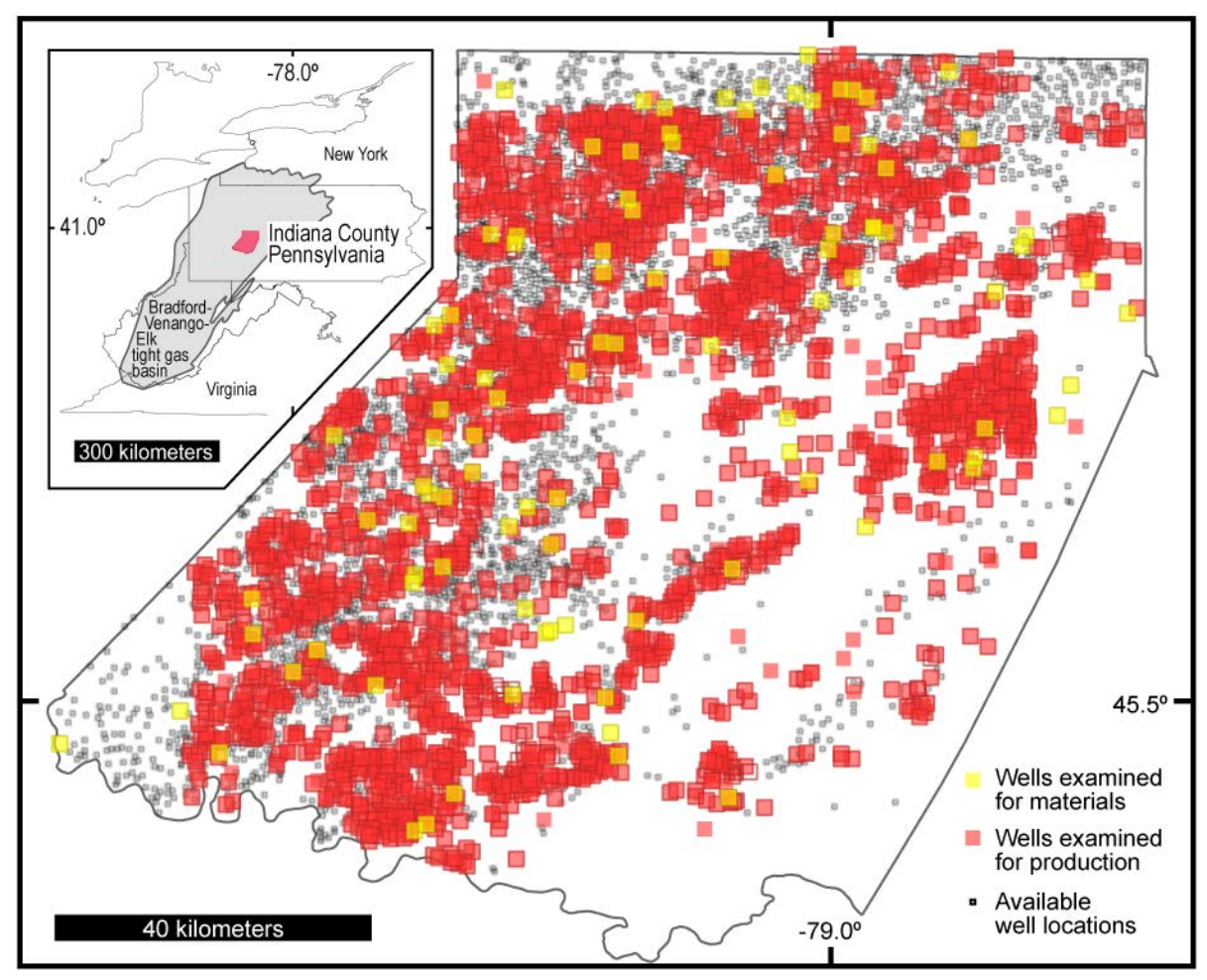

Figure 3. Depth-distribution of BVE wells. Elevation is that above sea level. Data are from the Pennsylvania Department of Conservation and Natural Resources (PADCNR). Wells have been drilled to other formations but $97 \%$ have been drilled to the depths of the Bradford, Venango, and Elk Formations.

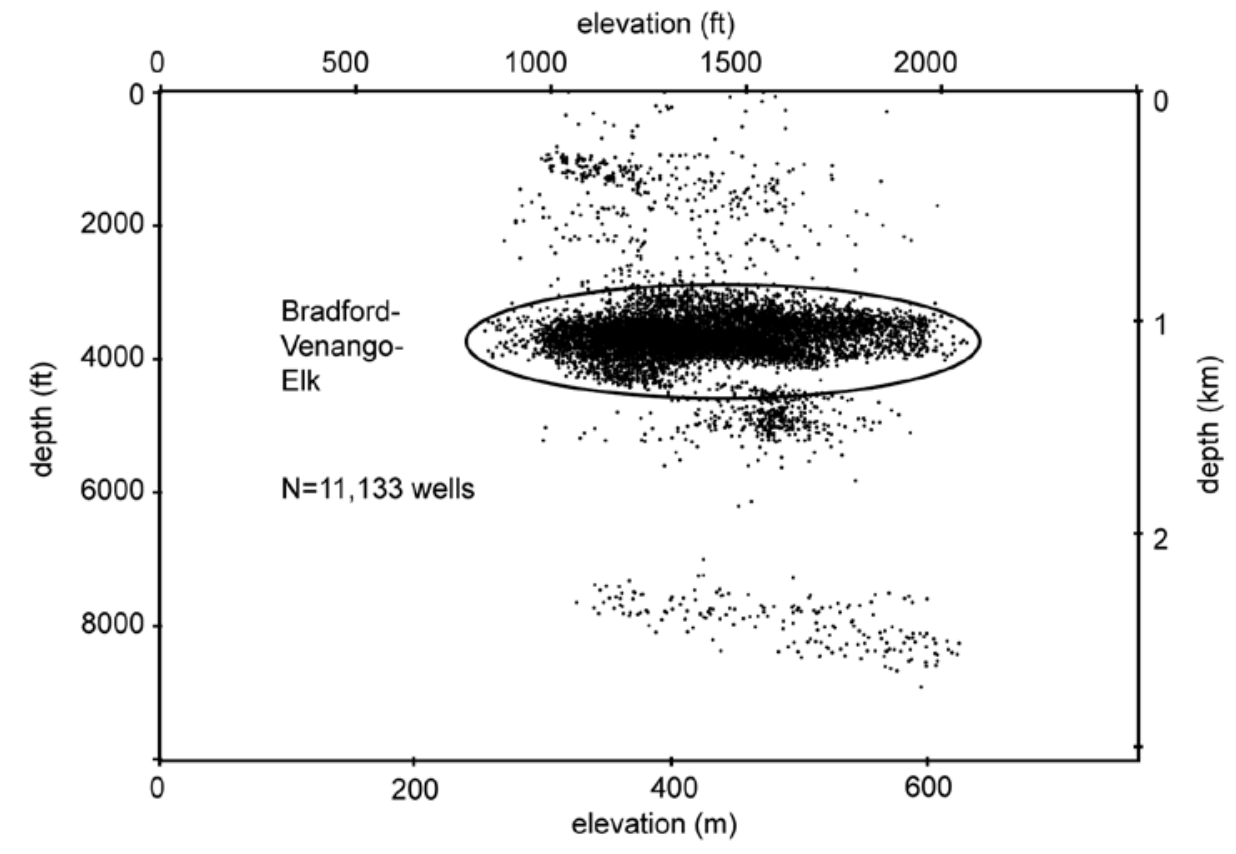




\subsection{Drilling and Production History}

The Bradford, Venango, and Elk plays (Figure 2) are tight natural gas formations that encompass the western half of Pennsylvania, northern half of West Virginia and small portions of Virginia, Kentucky, Ohio, and New York [1]. All three plays comprise the BVE natural gas basin (Figure 1). Indiana County is roughly within the center of the main drilling area of the BVE field. It is useful for context to note that in 2007 there were approximately nine residents for every natural gas well in Indiana County, Pennsylvania. Of the 10,468 Indiana County wells on file at the Pennsylvania Department of Conservation and Natural Resources (PADCNR) as of March 2007, 97\% were completed in the BVE natural gas play (Figure 3). The average depth of these wells is 1106 meters (3630 feet). The first BVE well in Indiana County was drilled in 1878 with peak number of wells (565) drilled in 1981 (Figure 4). After 1981, drilling intensity decreased rapidly until 1990 and is increasing steadily to this date. The market price of natural gas appears to have been the major driver in Indiana County's natural gas development (Figure 4).

Figure 4. Production and drilling history for BVE wells in Indiana County, Pennsylvania compared with the wellhead price per Mcf of natural gas. Price data are from the U.S. Energy Information Agency (EIA) [1]. Production and well data are from the PADCNR [18].

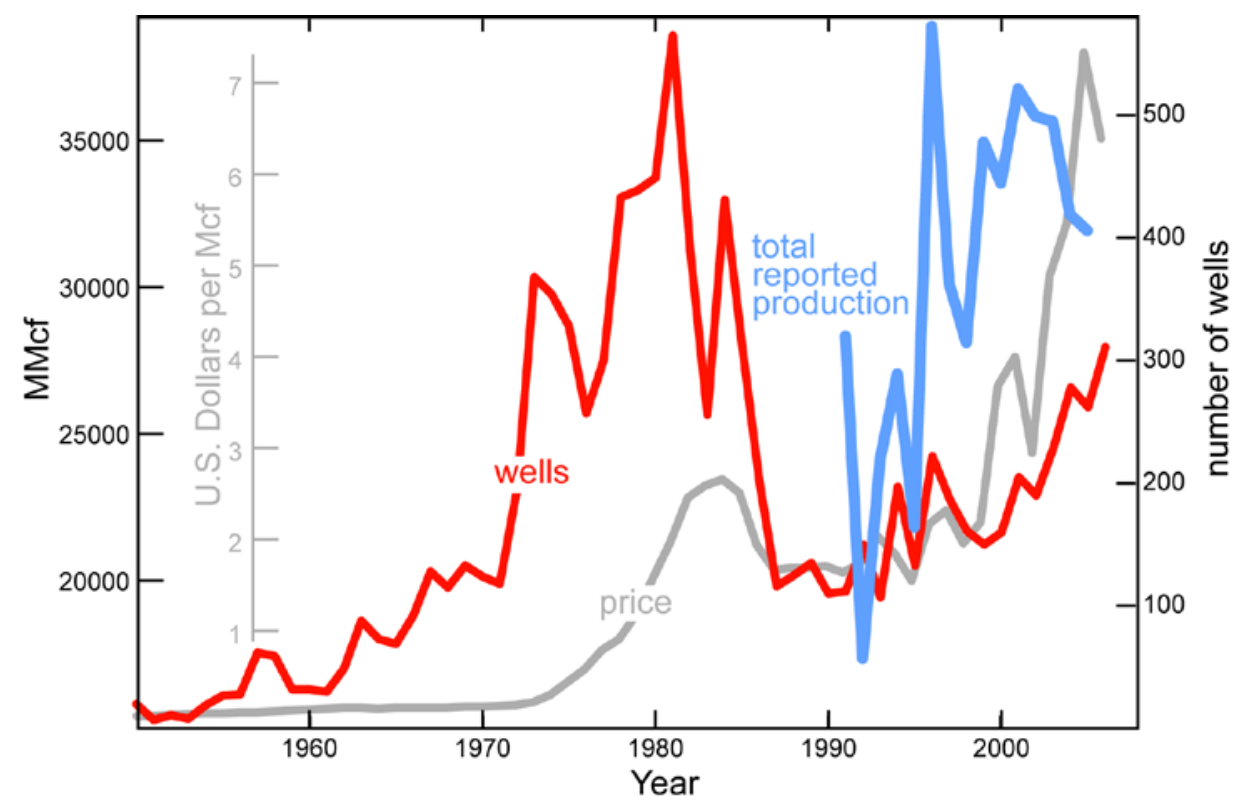

The BVE play is composed of multiple thin layers of siltstone and sandstone with low natural porosity. This type of formation requires the rock to be artificially fractured and eroded with explosive charges and high-pressure water containing various acidic chemicals. During this fracturing procedure sand is simultaneously pumped into the well as a material that acts as a prop (i.e., proppant) that holds open the artificial fractures.

Available production data from the PADCNR on the BVE natural gas play in Indiana, PA, dates back to 1980 with fewer than 100 reporting for the first ten years [18]. Between 1991 and 2001, between 5,000 and 7,000 wells were reported each year (Figure 4). For each year since 1991, natural gas from Indiana County has accounted for approximately $23 \%$ of the total gas produced in 
Pennsylvania. During this same time, the number of wells drilled account for $20 \%$ of all wells drilled in Pennsylvania. Total production increased each year, however average production per well decreased between 1990 and 2005 (Figure 5). Average production per well for 20 years was reported [19] with average initial production per well at 28.5 MMcf (78.1 Mcf per day) decreasing to less than 5.0 MMcf after 16 years. Of all wells drilled in Indiana County, approximately 97\% are successful natural gas producers. Unsuccessful wells typically have their production tubing removed, plugged with cement, and abandoned.

Figure 5. Average production per well between 1991 and 2005. The values were determined by dividing the number of wells drilled in a given years by the total production. Production and well data are from the PADCNR [18].

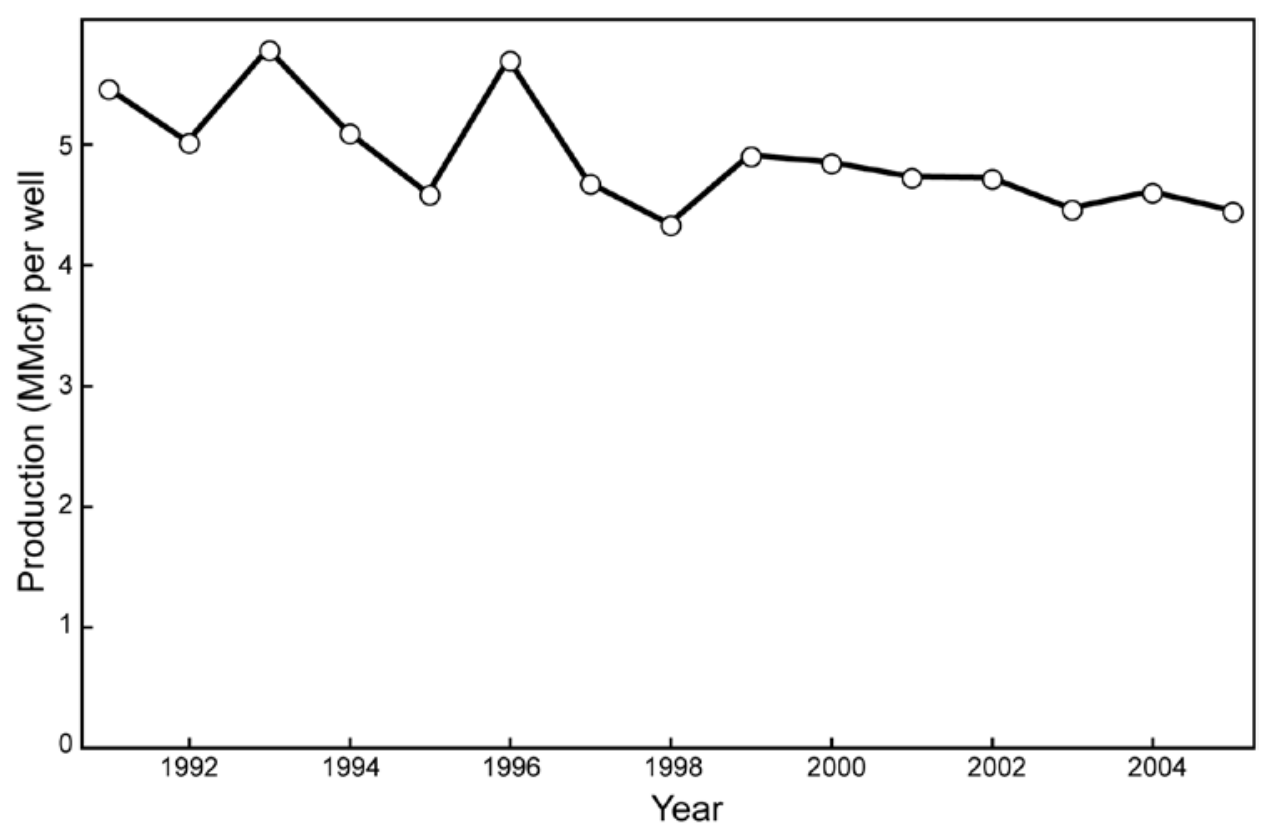

\section{Data Collection Methods}

Individual well costs are difficult to obtain because of proprietary restrictions on such data [20]. Summary reports on monetary costs are available from the U.S. Department of Energy, but these reports do not provide details on amounts of materials used. Despite these issues we obtained well information that includes location, total depth, and materials emplaced in the borehole for natural gas wells from archives maintained by the PADCNR. This allowed assessment of what comprises a typical well in this Indiana County. From the well information list in the PADCNR archive, 101 gas wells drilled between 1965 and 2004 were randomly selected using a random function in Microsoft ${ }^{\circledR}$ Excel $\mathrm{X}$ for Mac ${ }^{\circledR}$ for examination of materials used in drilling and completion. The wells were randomly selected in this way because it was not possible to convert all completion reports into a useable dataset while selecting completion reports that would cover a broad geographic area of the county. The selected wells appear to give an adequate geographic coverage. Wells that were abandoned after drilling because of a lack of natural gas, i.e., dry holes, are not included in this study. Materials consumed in natural gas well drilling were taken from well completion reports maintained by the PADCNR (Table 1). The reports for each well lists the amount of steel casing and tubing, cement, and 
fracturing fluids and proppants (sand) used in the construction of the well. Approximate diesel fuel consumption used in drilling and completion of the well were derived from personal interviews and checked against industry publications [21]. Drilling and completion diesel fuel numbers were derived from personal sources at drilling and well service companies in Indiana County and from private company reports for fuel use in other natural gas producing regions in the United States.

Table 1. Materials list for a typical natural gas well in Indiana County, Pennsylvania, with a depth of 3710 feet.

\begin{tabular}{lcc}
\hline \multicolumn{1}{c}{ Materials } & Amount & $\begin{array}{c}\text { Total Energy } \\
\text { per well (GJ) }\end{array}$ \\
\hline Average casing and tubing weight (U.S. short tons) & 31.88 & 1037 \\
Average cement (U.S. short tons) & 22.69 & 127 \\
Average stimulation Water (gallons) & 74,099 & $?$ \\
Average proppant/sand (U.S. short tons) & 144.82 & 3.77 \\
Drilling diesel fuel (gallons/day) & 450 & 886 \\
Completion diesel fuel (gallons/day) & 900 & 135 \\
Average well completion time (days) & 13.1 & - \\
Labor Cost $\quad$ Conversions & 176,331 & ? \\
Average Production (Mcf) with 4\% production loss & Conversion units & References \\
\hline & $25.3 \mathrm{GJ} /$ ton & {$[22-24]$} \\
\hline Raw Steel & $7.2 \mathrm{GJ} /$ ton & {$[22-24]$} \\
Manufactured steel pipe & $0.03 \mathrm{GJ} /$ ton & {$[25]$} \\
Limestone mining & $5.59 \mathrm{GJ} /$ ton & {$[25,26]$} \\
Cement manufacturing & $0.03 \mathrm{GJ} /$ ton & {$[25]$} \\
Sand (aggregate) mining & $0.15 \mathrm{GJ} /$ gallon & {$[27]$} \\
Diesel fuel energy content & $1.08 \mathrm{GJ} / \mathrm{Mcf}$ & {$[27]$} \\
Natural gas energy content & $0.59 \mathrm{GJ} /$ foot & This study \\
Energy cost for drilling & $\$ 51.00 /$ foot & {$[28]$} \\
Approximate dollar cost for drilling & & \\
\hline
\end{tabular}

United States Energy Information Agency data were downloaded from their website [1]. Data used in this study includes: (1) footage for all exploratory, development, and dry wells; (2) gross gas well withdrawals; (3) the number of natural gas exploratory and developmental wells drilled; and (4) nominal cost per foot of natural gas wells drilled. Data coverage is restricted to those wells drilled explicitly for natural gas-mixed wells that produce both natural gas and crude oil are excluded.

\subsection{Deriving EROI}

The EROI calculated here is for the mine mouth $\left(\mathrm{EROI}_{\mathrm{mm}}\right)$ and takes into account the embodied energy found in materials consumed in well construction. Energy quality is not considered and other energy costs are ignored because we consider them minor with respect to the costs presented here, e.g., physical energy employed by workers. An EROI ratio, which is a first approximation of EROI $\mathrm{mm}_{\mathrm{m}}$ is calculated for Indiana County using the following equation:

$$
\text { EROI }_{\mathrm{BVE}}=\frac{\mathrm{P}-\mathrm{s}}{\mathrm{S}+\mathrm{C}+\mathrm{p}+\mathrm{D}}
$$


Production, $\mathrm{P}$, and production loss from pipeline leaks, s, represent the energy returned. The energy equivalents of steel used in casing and tubing, S; cement used in the well, C; proppant used in fracturing, p; and diesel fuel used in drilling and well treatment, D, represent the energy inputs. Other energy inputs can be added, but were not directly available for this study.

The energy requirements for the BVE play wells in Indiana County are assumed to be close to the minimum cost of drilling a natural gas well. The minimum energy requirement is 0.59 gigajoules per foot. This minimum energy cost per foot is used to calculate the average energy cost per foot, $E_{f}$, of natural gas extraction in the U.S. on the basis of monetary cost per foot (assuming that energy cost is approximately proportional to monetary cost and that energy costs for BVE wells in Indiana County have remained constant):

$$
\mathrm{E}_{\mathrm{f}}=\mathrm{E}_{\mathrm{m}} \frac{\mathrm{C}_{\mathrm{AN}}}{\mathrm{C}_{\mathrm{m}}}
$$

The minimum monetary cost per foot is $C_{m}$, which is equal to $\$ 51.00$ per foot for the year 2000, $\mathrm{C}_{\mathrm{AN}}$ is the average monetary cost per foot for the nation (U.S.), and $\mathrm{E}_{\mathrm{m}}$ is the minimum energy cost. This average energy cost per foot is then multiplied by the total footage drilled for a given year such that:

$$
\text { EROI }_{U S}=\frac{P_{t}}{E_{f} F}
$$

The total production, $\mathrm{P}_{\mathrm{t}}$ is from gross gas withdrawals, $\mathrm{E}_{\mathrm{f}}$ is the average energy cost per foot, and $\mathrm{F}$ is the total footage drilled for all exploratory, development, and dry wells. In this EROI calculation the monetary and energy costs, footage drilled, and production are used to approximate an ratio for $\mathrm{EROI}_{\mathrm{mm}}$. Another indicator of the natural gas drilling effort that may useful is the total number of gas wells drilled per year. While admittedly speculative, we assume here that as the numbers of wells are increased there may be a corresponding increase in infrastructure. This infrastructure increase may be used to give an indication of energy inputs beyond the mine mouth boundary, i.e., point if use $\left(E \mathrm{EI}_{\text {pou }}\right)$ as defined in the introductory portion of this volume. If so, then the number of wells drilled in a given year can be used as an approximation of transmission and processing costs and losses such that $\mathrm{EROI}_{\text {pou }}$ for the U.S. may be estimated by:

$$
\text { EROI }_{\text {total }}=\frac{\mathrm{P}_{\mathrm{t}}}{\mathrm{E}_{\mathrm{f}} \mathrm{F}} * \frac{\mathrm{W}_{\text {by }}}{\mathrm{W}_{\mathrm{t}}}
$$

The number of wells drilled for a base year $\mathrm{W}_{\text {by }}$ is the same year used to derive real from nominal dollars. The number of wells drilled for any given year, $\mathrm{Wt}$, divides the number of wells for the base year. The number of wells does not account for all infrastructure however, we use the number of wells drilled as a factor that takes into account the influence of field expansion and the required pipeline development. A more accurate calculation would add the energy costs of infrastructure, which is clearly not taken into account in our analyses. 


\subsection{Deriving Energy Intensities of Materials Used}

To tally the energy costs of drilling and completing a BVE play well we examined the amounts of steel for casing and tubing, cement used to set the casing in the borehole, water and sand used for treating the well, and diesel fuel for all aspects of well construction. Many other materials, e.g., fuel for transporting personnel to the well site, are commonly used in the construction of a natural gas well. We consider the energy cost of these other materials as small compared to the entire energy cost of the proceeding materials and would make a minor contribution to the EROI calculation. This assumption appears reasonable after examining "application for expenditure" forms from private industry. Unfortunately, these forms contain proprietary information and cannot be published. Some other materials such as drill bits may make a significant contribution to energy cost of a well; however, reliable information on the manufacturing energy cost is not readily available. While we did tally the amount of water used (i.e., fracture fluids), there was no clear way to arrive at an energy equivalent for water use.

Calculating the energy cost for making steel (Table 1) is difficult because it is unknown what quantity of secondary steel (i.e., steel manufactured from scrap using electric arc furnaces) is used for casing and tubing. Secondary steel has been estimated to cost between 11.3 [22] and $11.8 \mathrm{GJ} / \mathrm{ton}$ [23]. For primary steel derived directly from iron ore the energy cost is estimated to be between 23.4 [22] and $26.0 \mathrm{GJ} /$ ton [23]. According to Worrell [23] there appears to be a decrease in the average energy consumption by the steel industry per ton of product of almost 35\% over a couple of years in the early 1980s, which should be considered when calculating the energy cost of a well at least prior to 1982. The decrease in average energy consumption is probably due to the closure of many older integrated steel mills and an increase in the number of mills that use recycled steel [23].

Also important to note is that several energy intensive materials required for steel making are excluded from the energy equivalents. Stubbles [22] points out that such excluded items include electrodes, ferroalloys, refractories, and imported direct reduced iron. Also excluded from the energy cost of steel is the mining cost of coal for coke and limestone for lime. According the U.S. Department of Energy [25], coal produced in the eastern United States is estimated to have an energy cost between 0.31 and $0.003 \mathrm{GJ}$ per ton. Lime is used in the steel industry to remove impurities during the steel making process and comes from the thermal decomposition of calcium carbonate, i.e., limestone. The process of mining and making lime is similar to that for cement, which has been estimated to have an energy cost of $5.3 \mathrm{GJ}$ per ton [23]. Coke and lime requirements per ton of steel are 50 and 120 pounds, respectively [22]. Coke and lime combined adds only $0.3 \mathrm{GJ}$ of energy cost to each ton of steel, which has a small effect on the final net energy requirements for natural gas well construction.

We could not find direct energy costs associated with the manufacturing of petroleum specific casing and tubing from steel in any published literature. However, the energy costs for forming and finishing, which includes manufactured pipe is estimated to be 7.2 gigajoules per ton [22,23]. This energy cost for petroleum specific tubing is likely to be more than basic structural tubing because of stringent requirements as outlined by the American Petroleum Institute.

The energy costs for producing crushed and broken limestone and other rocks are derived from a 2004 report to the U.S. Department of Energy on energy use in the mining industry [25]. The estimated energy costs of mining and processing limestone minus calcining (lime production) is 0.026 GJ per 
ton. Cement manufacturing is energy intensive at 5.59 gigajoles per ton because of the heat needed to decompose calcium carbonate to lime [25,26]. Sand used as a proppant requires a specific grain size and grade that must be mined, crushed, sieved, and transported in a similar manner as limestone. Since we could find no studies on the energy requirements for sand production we use the same energy cost values as used for the mining of limestone.

The energy equivalent of natural gas is $1.08 \mathrm{GJ} / \mathrm{Mcf}$ [27]. Production for each well is measured at the wellhead. Most natural gases require processing to remove other liquid fuels and impurities, which results in a reduction of volume of the extracted natural gas. The U.S. Energy Information Administration estimates this volume reduction (shrinkage) to be approximately 4\%, which we use to correct the energy produced at the wellhead since natural gas (methane) is what is being examined in this study. The diesel fuel energy equivalent is derived from the same report as the natural gas equivalents [27].

\section{Results}

Individual well production data from Indiana County are for the years 1984 through 2003 while material data are for the years between 1964 and 2005. On the basis of all available production data from 2486 wells (Figure 6), average production per well increased during the 1980s and then generally decreased or remained flat until the present. Average total production per well is 184 MMcf between the years 1985 and 2003. A log curve fitted to the average of all production data gives $\mathrm{R}^{2}$ value equal to 0.97 (Figure 7). Average first year production data shows a decrease in production after 1988 (Figure 8). On the basis of subtle trends shown in Figure 6 and Figure 8 we grouped the wells to show multi-year trends that show decreasing average production (Figure 9). Wells were randomly selected using a spreadsheet random number function (Figure 2). On the basis of 101 wells, materials used in the well construction show no clear trends over time, but the time it takes to drill a well generally decreased between the 1960s and 1980s and remained flat until the present (Figure 10). Average natural gas production (Figure 7) and the average of materials consumed (Figure 10) were converted to their energy equivalents (Table 1). The average EROI for a gas well in the BVE tight gas play in Indiana County, Pennsylvania over this time period is 86.96 (Figure 11). Year to year production changes do not show a correlation with year-to-year changes in available data (see data appendix). EROI fluctuates with respect to well production and shows a general decline from the 1980s when the EROI was as high as 120:1 to 2003 when EROI was equal to 67:1 (Figure 12). 
Figure 6. Average production profile for wells drilled each year between 1984 and 2002. Data from the PADCNR.

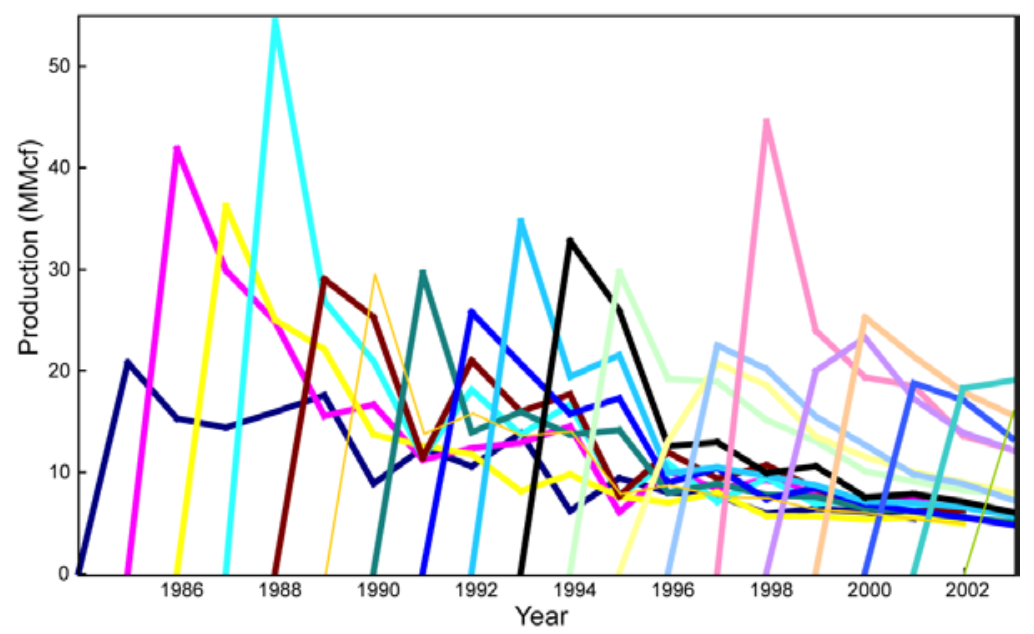

Figure 7. Production profile. All production data (total production over the life of a well) shown at a log scale with an average production curve fitted to the data. The y-axis is shown at a logarithmic scale in order to show the complete range of available production data. Downward deflection of older portion of curve is due to logarithmic decline.

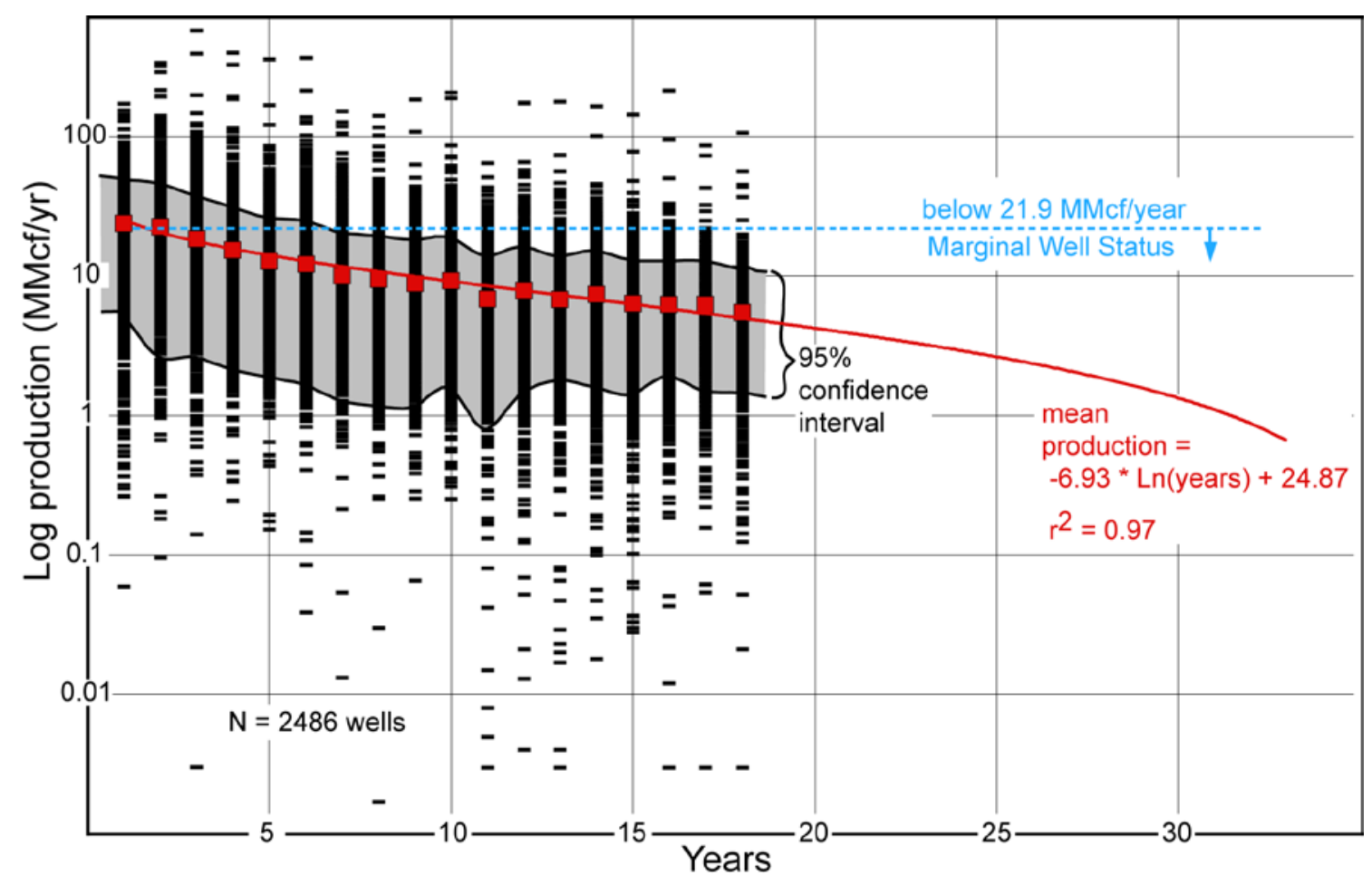


Figure 8. Average first year production. Total production after the first year of a well's life is generally considered to be a good productivity indicator.

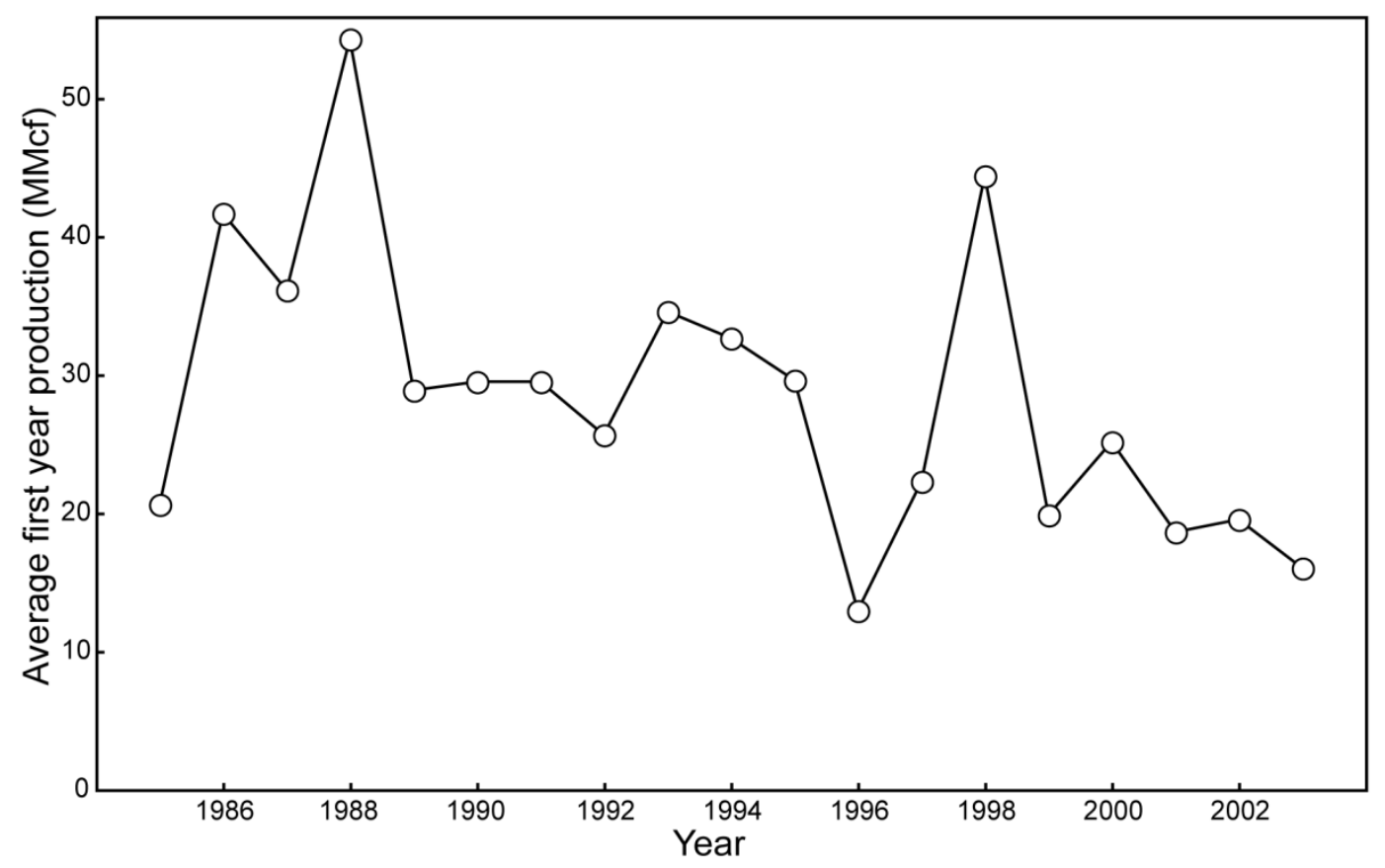

Figure 9. Production groups on the basis of multi-year trends defined by first year production.

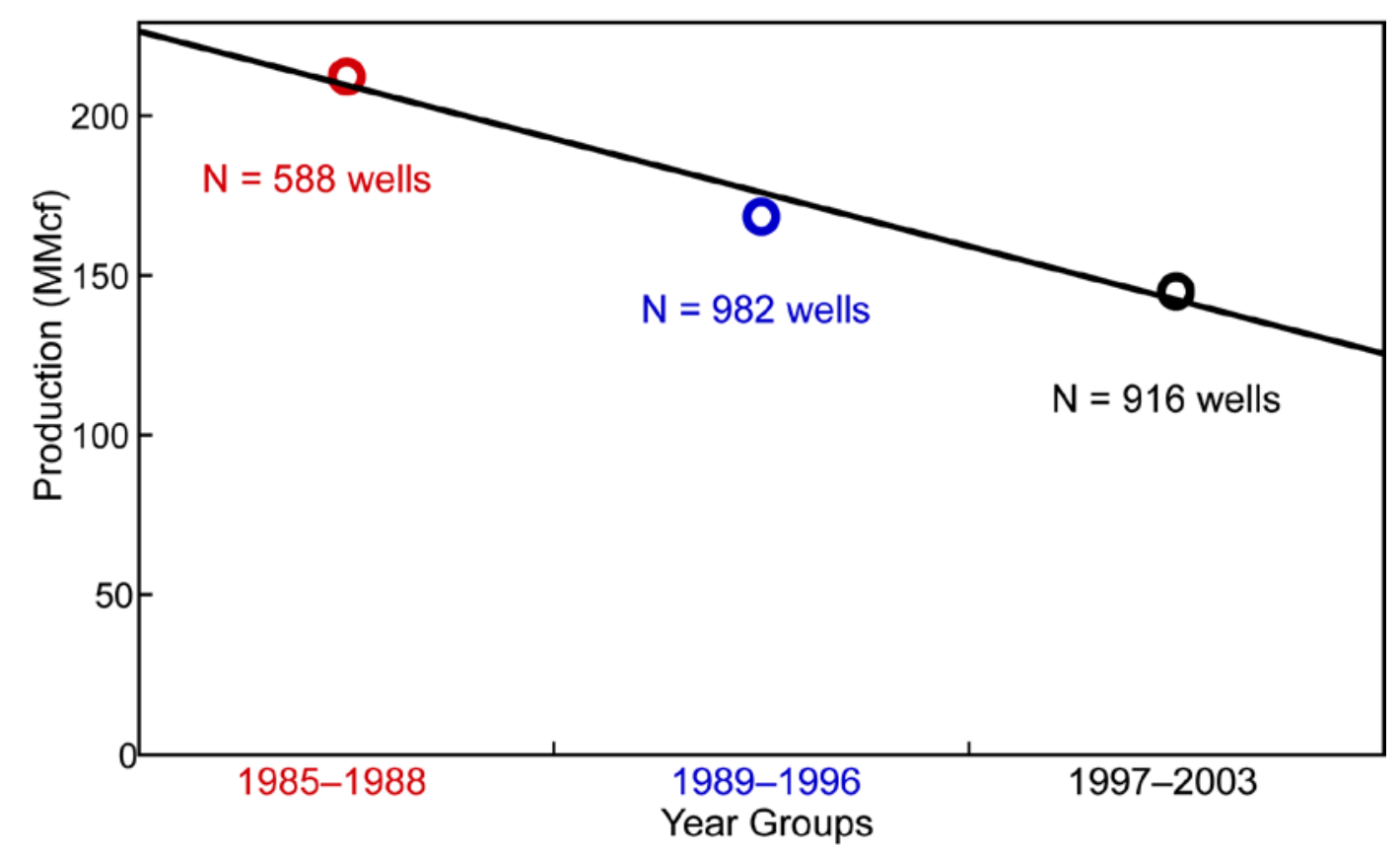


Figure 10. Materials consumed in well construction and drilling time for Indiana County, PA.

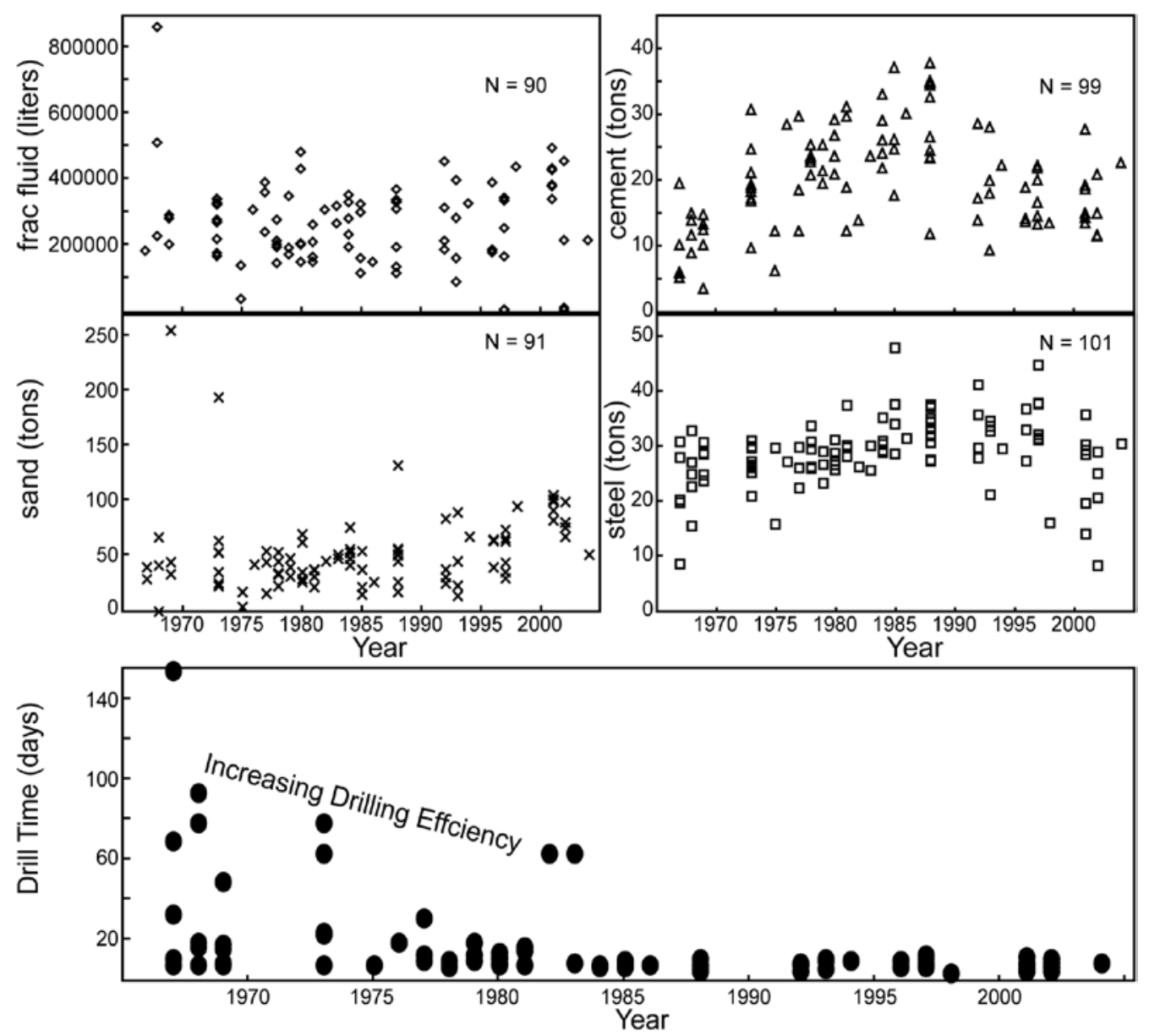

Figure 11. Energy inputs and outputs used to calculate EROI of an average well in the BVE play in Indiana County, Pennsylvania.

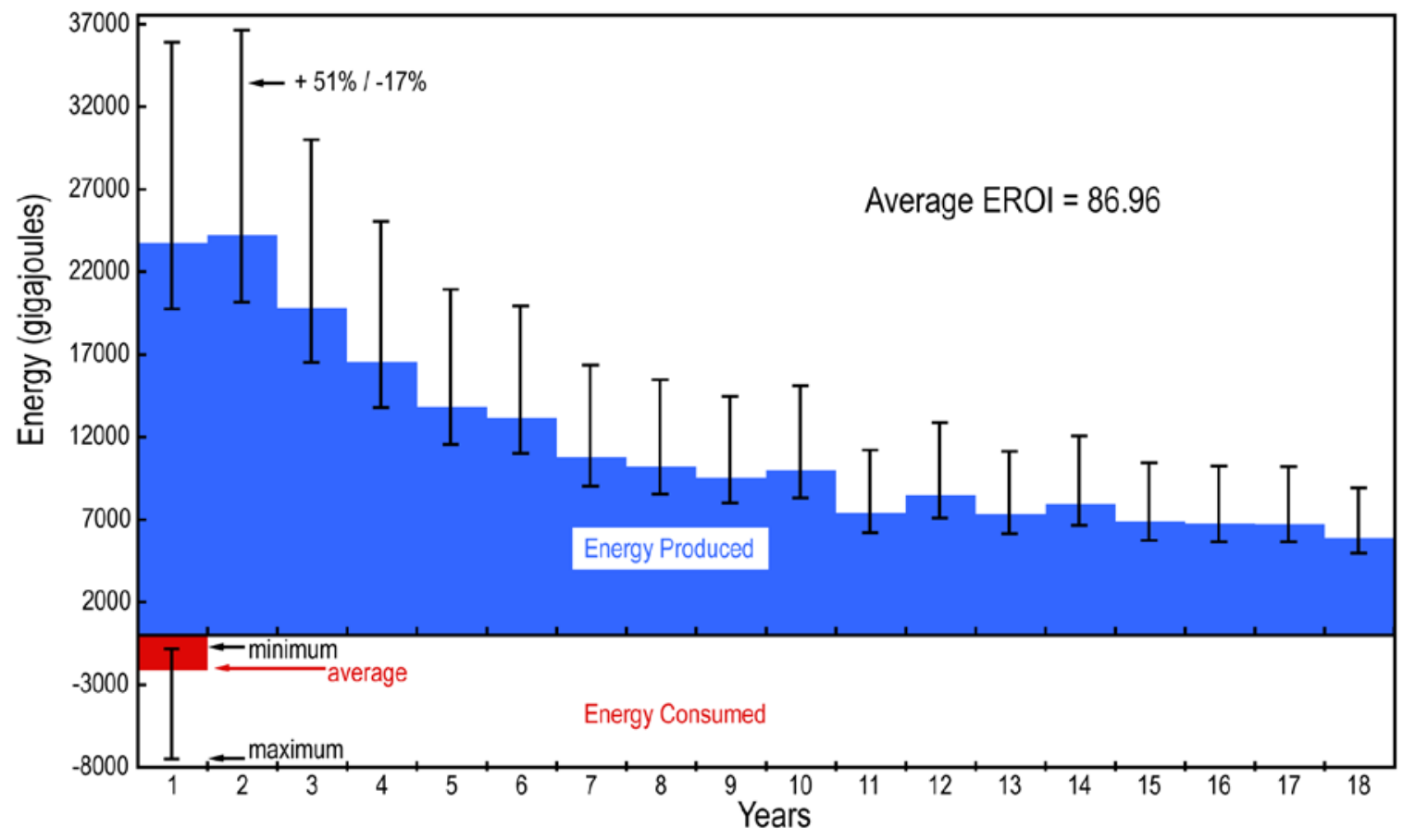


Figure 12. EROI time series and linear prediction for BVE play in Indiana County, Pennsylvania.

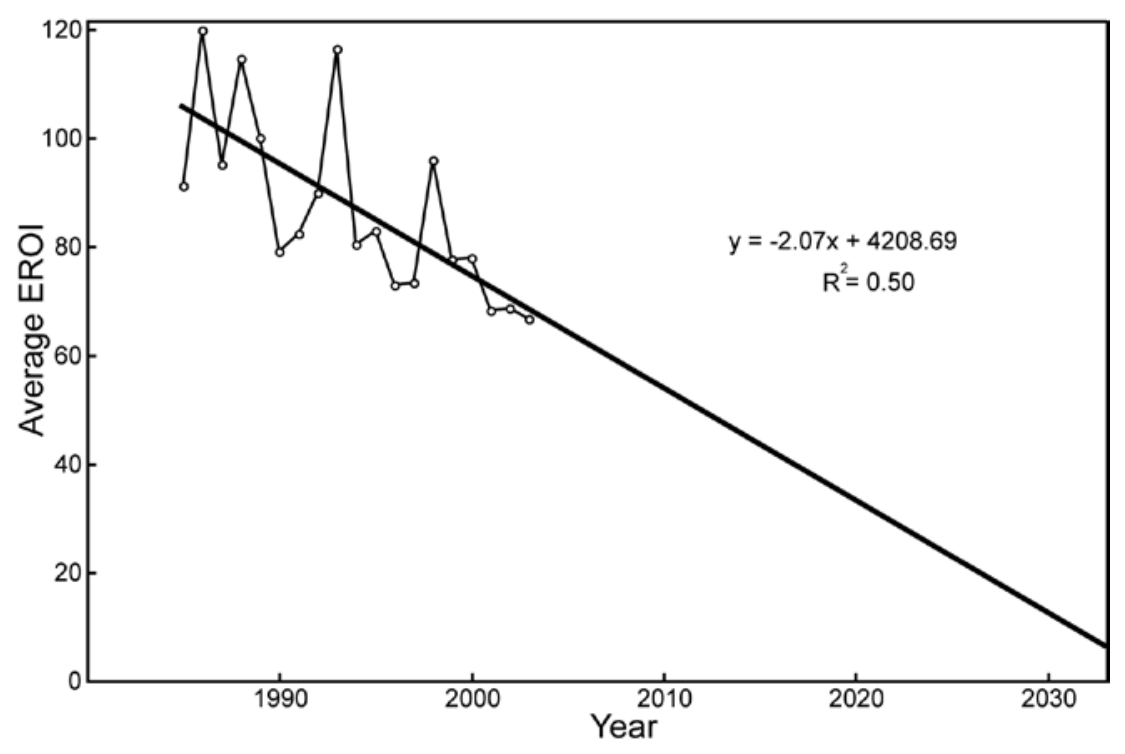

On the basis of materials consumed, BVE tight gas wells in Indiana County have an energy cost of 0.59 gigajoules per foot. On the basis of private industry reports and interviews, the same wells in the early 2000s appear to have an approximate U.S. dollar cost of 51 dollars per foot. We used this cost information as a baseline together with well data from the U.S. Energy Information Agency (EIA) to construct an EROI time series for the entire U.S. natural gas drilling system (Figure 13); dollar and energy cost are assumed to be approximately proportional. Drilling cost per foot data from the EIA is corrected for inflation on the basis of 2000 U.S. dollars. The difference between the monetary cost of an Indiana County BVE well and the average gas well in the U.S. is normalized to the year 2000 to create a scaling factor to multiply with the baseline energy cost. The resulting EROI time series can only be calculated back to 1967 because of limited cost data. Scaling the energy cost in this way shows that upstream EROI appears to have peaked twice above 200:1 in the early 1970s and 1990s. Calculating an additional scaling factor for energy cost on the basis of the number of wells drilled annually appears gives a much lower EROI, but shows the same general trends. The total EROI ratio calculated by scaling the energy costs using cost per foot data is multiplied by the scaling factor calculated from the number of wells drilled; this shows a similar trend with values mid way between the other two EROI trends. Between 1992 and the present the EROI for U.S. natural gas appears to have decreased by one order of magnitude and is declining at a steady rate. A comparison of production per foot drilled to cost per foot drilled shows two periods of increasing cost with decreasing production. Each period corresponds with decreasing EROI as well as known historical gas crises. 
Figure 13. EROI (A) and productivity for the United States (B). EROI (c) is calculated on the basis of cost differences between our baseline well study and the average cost per well for the United States using footage drilled, and gross withdrawals from gas wells (Equation 3). EROI (d) is calculated as in (c), but the EROI ratio is multiplied by a factor derived from the number of wells drilled in a given year (Equation 4). Each EROI curve is a two-point moving average of the EROI calculated for the years between 1967 and 2007. Counterproductive periods in (B) are defined as years when cost per unit depth increases as production per unit depth decreases over several years. All data are from the EIA [1] except for the well-cost data for our baseline well. Real U.S. dollars are derived from nominal U.S. dollars by correcting for inflation from the year 2000.

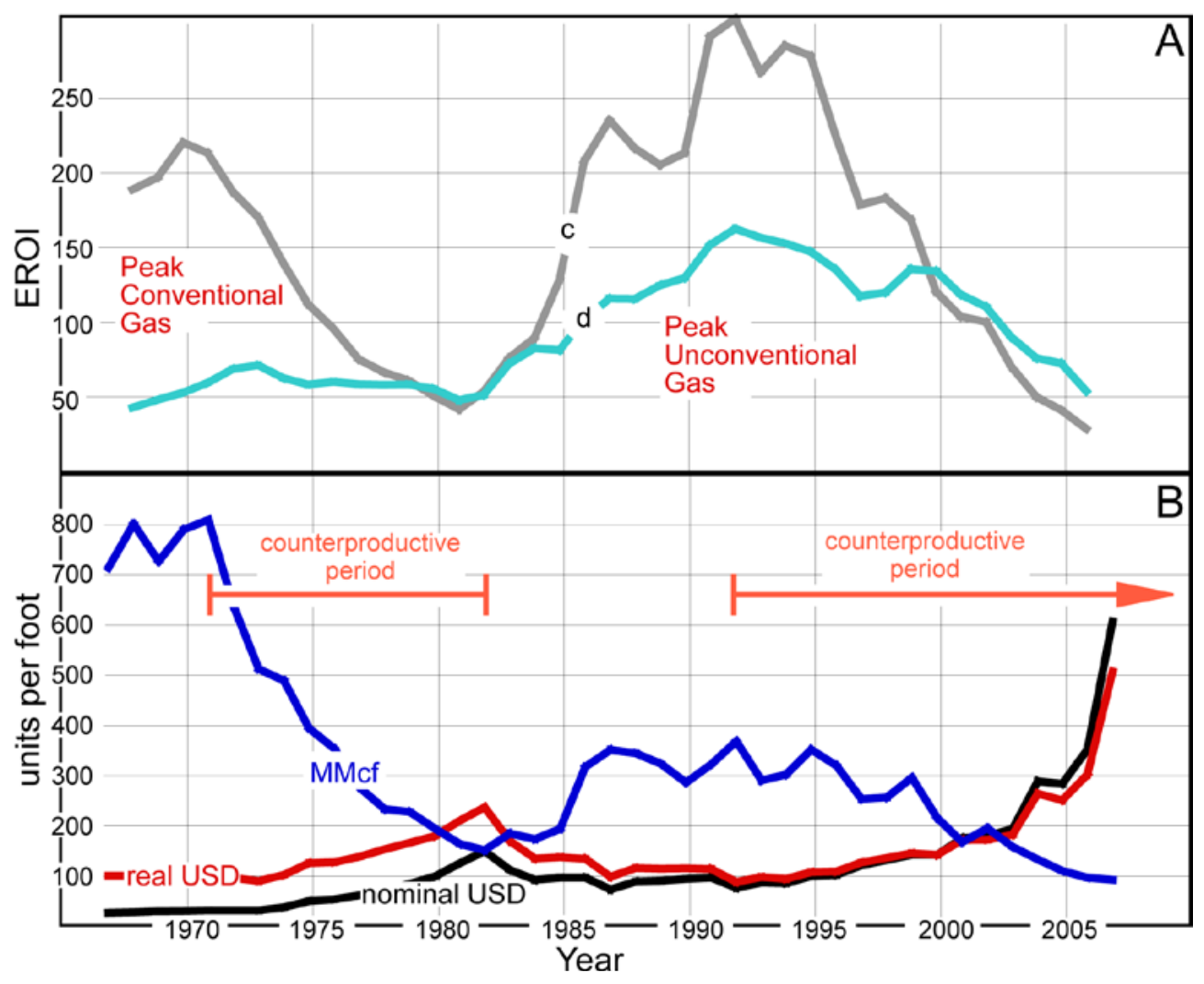

\section{Discussion}

\subsection{Production Characteristics}

Total natural gas production from Indiana County has been increasing since detailed government records started in 1991 (Figure 4); however, total production values may be misleading. For example, if this production data is compared to the number of wells reporting, the total production per well is decreasing by approximately 0.07 MMcf per year (Figure 5). Peak production in Indiana appears impossible to assess because of the lack of detailed records dating back before 1991 . However, total production roughly corresponds with the number of wells drilled because production decreases rapidly over several years. This means that peak gas likely occurred in the late 1980s with a second minor peak in total production occurring in the late 1990s. Sparse information is available, but what does exist seems to suggest that the gas fields in Indiana County are in decline. Another peak in production 
may seem possible, but the recent decrease in production per well coupled with the high geographic density of well sites (Figure 2) appears to suggest otherwise.

Other indicators suggest that the BVE play in Indiana County is in decline. These include lifetime production per well (Figure 6), production for the first year (Figure 8), and multi-year trends on expected production (Figure 9). Average production of a typical BVE well in Indiana County was assessed at 180 MMcf for 16 years after a well was drilled in 1996 [19]. However, these numbers are not reliable. The average productivity of wells drilled in 1986 actually came in, after 16 years, higher at 234 MMcf. The earlier, lower estimate is likely due to insufficient data in 1996. The expected average production of BVE wells in Indiana County did not decrease to the previously estimated levels until after 2001. The year-to-year changes in production appear to be subtle (Figure 6) and highly variable (Figure 7). An average logarithmic-scale (decline) production curve shows a good fit to all of the production data for all years and suggests that year-to-year production has not changed much over the past three decades. However, the average production of all wells for all years seems to hide the subtlety of the production changes from year-to-year as evidenced by production per well (Figure 5) and first year production values (Figure 8). Changes in productivity are occurring over several years such that a year-to-year analysis of production does not capture the all of the field production characteristics. First year production values do show three trends. First, average first year production increased during the 1980s. Second, average first year production decreased to approximately 30 MMcf in 1989 with a sharp drop in 1996. Third, first year production picked up again in 1998 and has gradually decreased since. We interpret the peaks in first year production to reflect minor discoveries within the field with subsequent declines. Splitting the production data accordingly into groups indicates an overall production decrease with each well group contributing to an overall decline in production per well with time (Figure 9), i.e., the Indiana County BVE play is in decline.

\subsection{Materials Consumed}

Materials used in well construction can vary significantly. For example, when examining 101 well records, the amount of casing used in a well varies by $44 \%$ at two standard deviations. However, drilling depth varies by only $15 \%$ at two standard deviations among well samples such that casing and tubing amounts would be expected to vary by at least this much. The amount of variation in well casing is due to the use of varying casing diameters among different well operators. It is not known by us whether the size of casing and tubing affects production or if the different sizes reflect the well construction programs of different companies. In our estimation, casing and tubing account for 50\% of the energy cost. This is in contrast to the typical 10-20\% monetary cost of casing and tubing for drilling elsewhere [20,21]. Because casing and tubing account for a large percentage of the energy consumed in well construction and the variation in their use is high, it is necessary to calculate a minimum and maximum energy cost for the wells in Indiana County.

Diesel used for drilling and completion can contribute greater than $90 \%$ of the energy cost of drilling a natural gas well in Indiana County. Accurate numbers on amount of fuel used in the construction of these wells was difficult to obtain. What little information we acquired was checked against private industry reports from similar wells drilled elsewhere. Variation in fuel consumption is expected to be significant between wells because of the varying age of engines and equipment and the 
time to drill. Time to drill varies between three and 44 days, so fuel consumption would be expected to have a similar variation. At 450 gallons of diesel fuel or 886 GJ per day any inefficiencies and complications in the drilling process such as old equipment, broken bits, and twisted, broken, or stuck drill pipe can add a significant energy cost to well construction.

\subsection{EROI}

The average well drilled in Indiana County between 1985 and 2003 has an EROI of approximately 87:1 (Figure 11), which is a high energy return compared to other non-fossil fuels, but is consistent with EROI of other high-EROI fossil fuels [29]. EROI suggests that natural gas is competitive with respect to other commercially available sources of energy such as nuclear, wind, solar, and biomass. This makes sense when considering the relatively low price of natural gas and its predominance as an industrial fuel.

The high EROI of these marginal fields suggests that natural gas will continue to be a useful fuel despite decreasing reserves and marginally economic fields. Wells with above average material consumption can still yield a high rate of return (Figure 11). More efficient construction of wells could increase the profit margin of production companies and would likely have the effect of extending the economic life of the entire field. The highly variable material consumption of well construction in Indiana County could be reduced, especially in terms of diesel fuel consumption, drilling rate, and the use of recycled steel in casing and tubing. Production is also highly variable, however, the geologic complexity of the field appears more difficult to predict. New well treatment practices, i.e., hydraulic fracturing, may increase productivity in the BVE tight gas field, but the energy and environmental costs of such new practices are not yet known.

EROI calculations appear to be useful for predicting the future of the BVE tight gas field in Indiana County (Figure 12) and could be modeled on the existing data with constraints from the remaining space that is available to drill. For example, the EROI appears to be declining as drilling area increases which suggests that there may be spatial relationships between production and well density, i.e., field depletion due to infill drilling. This is important new information not only for local government economic planning, but also for the state of Pennsylvania since Indiana County accounts for nearly one quarter of total state gas production between 1985 and 2003. A simple linear model on the basis of the average EROI for each year since 1985 suggests that the field may be economically productive just beyond 2030. This is an oversimplification because the historical data show that field development may find new areas with higher producing wells. Also, increased efficiencies in drilling practices periodically cause the energy returns to fluctuate. However, it is an accurate prediction that BVE natural gas is a finite resource that will continue to dwindle. Technology advances and increased efficiencies will only serve to cause fluctuations in gas production that has an overall downward trajectory. Currently, it appears that technological effects that increase production are receding because average production per well is decreasing.

The EROI calculated here is high compared to previous EROI estimates for natural gas [7,29-32]. However, the EROI range calculated here is a conservative estimate. The "true" values for EROI of a natural gas well should be lower because of several factors. First, there are costs that cannot be accounted for at this time because of insufficient data. Several materials such as sorted sand, 
water, acids and gels used in well treatment, drill pipe and bits, equipment repairs, etc., require extraction, manufacturing, and transportation. Second, refining and distribution energy costs that will further decrease EROI are excluded. Energy efficiency information in processing natural gas to remove natural gas liquids and other impurities and the transmission of natural gas to and from the processing plant are not available; however, these are expected to contribute at least a few percent of the total energy cost of marketed natural gas. Third, according to the U.S. Energy Information Administration, the dry holes that are drilled in petroleum exploration and production account for more than $10 \%$ of all wells drilled in the United States. This alone should have a significant impact on the large-scale EROI calculations and individual fields with higher failure rates.

Our EROI findings (67:1 to $120: 1)$ are much larger than the (10:1 to 20:1) EROI modeled by Gately [32], which suggests that marginal wells in the Appalachian Basin require much less effort for equal amounts of gas acquired by offshore wells in the Gulf of Mexico. Increased drilling effort in complex production environments requires large volumes of gas compared to the minimal volumes found in some less complex production environments. Low volume and highly complex-drilling environments, such as some shale gas reservoirs could ultimately show relatively low EROI values. As unconventional natural gas fields become increasingly exploited, the energy returned on the energy invested may become a limiting factor in economic development. Since it appears that offshore gas will no longer be a major contributor to the total U.S. natural gas production (offshore rig counts from the EIA [1]), sources like shale gas and imported liquid natural gas should be assessed for comparison.

\subsection{EROI for the United States}

We assume that the energy cost for drilling a well in the BVE field of Indiana County serves as a baseline energy cost for natural gas drilling in the United States. The average monetary cost per foot for natural gas wells in the U.S. [1] between 2000 and 2005 is three to five times higher than the cost of BVE wells in Indiana County. In 2007, the average cost of a gas well in the U.S. increased to roughly eight times that of a BVE gas well in Indiana County, which is expected on the basis the cost of unconventional gas wells $[33,34]$ that are increasingly dominating U.S. gas development. We can make another assumption that the real dollar cost per foot of a gas well is proportional to the energy cost per foot. The remaining data needed to make an EROI calculation are on record with the U.S. government. Gross withdrawals data from wells specifically drilled for natural gas are only available from 1967 [1], which limits our estimations of energy returned in the past. Costs per foot data are currently available up to the year 2007. Another limitation of the data is that footage drilled for natural gas wells cannot currently be controlled for dry holes so that all footage drilled must be considered together. Dry holes cost less money and therefore our EROI time series calculation likely overestimates energy costs. However, the accurate energy cost would not change the overall EROI trend as it is largely controlled by the differences between production and total footage drilled.

The EROI of natural gas production peaked twice in the U.S. The first peak in 1971 corresponds with Hubbert's [35] predicted peak gas and the actual peak in conventional natural gas production [1]. EROI decreased between 1971 and 1982 because of a decrease in total gross withdrawals, a two-fold increase in real dollar cost per foot, and a four-fold increase in the number of wells drilled. This decline likely reflects the inability of technology to keep pace with declining conventional gas 
reservoirs. A corresponding increase in research on unconventional gas resources occurred over this same interval [36]. This research coupled with increases in the price of gas was successful at driving technological efficiency in field development and identifying new resources. EROI climbed rapidly between 1982 and 1987 largely as a result of offshore gas production and then increased to the second peak 1993 because of increased production from unconventional reserves. Marketed production during this time was supplemented by contributions from Canada and a continuing decrease in flaring/venting of natural gas contained in crude oil wells. Gas that would be typically flared or vented represented more than $25 \%$ of gross gas withdrawals in the 1940 s and decreased to $0.05 \%$ by 1982 . Also, gross withdrawals from gas wells continued to increase despite fewer wells being drilled. This increased production per well is likely a result of new resources and technology. All available natural gas data for the U.S. suggests that we are currently in a depletion trend. EROI has declined rapidly from 1993 until the present because gross withdrawals from gas wells have decreased with respect to an increased number of wells drilled and rising drilling costs. The current decline in EROI is due to the same factors that contributed to the EROI decline of the 1970s, however the difference is that there does not appear to a new gas resource beyond shale reservoirs. Also, the real monetary cost of drilling has increased by almost twice as much as it did during the conventional gas decline of the 1970s. Unconventional resources are maintaining production [1], but possibly at an increasingly higher energy cost. These drastic changes in drilling cost and production should control the current trend in natural gas EROI for the U.S.

Our analyses of U.S. EIA data suggest that there are at least two counterproductive periods in the history of United States natural gas exploitation. We use the term counterproductive because increased drilling efforts are yielding production results that are opposite of what we might expect-as one works harder there should be a corresponding increase in benefit. The first counterproductive period (Figure 13) should serve as a historical warning of what is to be expected, which occurred over a ten year period after conventional natural gas peaked in the early 1970s and ended when new gas supplies (e.g., Gulf of Mexico) were discovered in the United States. Relatively severe economic disturbances occurred during the bust and boom, i.e., beginning and end, of this counterproductive period. The second counterproductive period began in the early 1990s and has continued for nearly two decades to the present. If the historical precedent of the first counterproductive period was matched (Figure 13), then we should have had a new gas source made available in 2001. This new source did not materialize. There are no more new gas sources beyond shale reservoirs within the United States that are predicted to increase production per well or EROI. Shale gas has been touted as a new and abundant gas source, however the shale gas production has yet to show an impact on production per well. In fact, since the beginning of the current counterproductive period, the real monetary cost per foot of natural gas extraction in the U.S. has increased exponentially to more than six times that of 1993; and production per well has decreased to levels not seen since the beginning of the last century. This seems to suggest that the number of wells drilled annually needs to be continually increased to maintain overall production levels, which has been relatively constant for a few decades. Any economic perturbation similar to that of the first counterproductive period of the 1970s and 1980s could cause domestic gas production to drop at a relatively fast rate with corresponding economic consequences. 


\section{Conclusions}

This research provides the first publicly available analysis of the direct energy requirements, albeit somewhat incomplete, for natural gas well construction. The materials consumed in natural gas production have never before been incorporated into an EROI analysis. As such, the data in this research should provide an empirical check against EROI models based on dollar cost analysis. This research also underscores a dearth of information that is needed to accurately calculate the energy costs of energy production and to make predictions about the future economic viability of gas fields. Such information will be critical for future economic development in this region and larger economic systems.

There are parallels between the BVE play in Indiana County and the total natural gas extraction system of the U.S. Total production for both has increased to a plateau that has remained relatively unchanged for at least a couple of decades. However, first year production and total production per well has been decreasing for quite some time, i.e., increased drilling effort has only maintained production levels. Increases in drilling effort in both the larger and smaller gas systems are showing the same results. EROI for the BVE play in Indiana County and the U.S. are currently both declining at a linear rate, which might reflect similar drilling effort and production characteristics. A cursory examination of the well density in Indiana County suggests that the heavily drilled area is likely approaching a limit controlled by the available drilling space. Since the U.S. production trends are similar to Indiana County it may be possible that the national gas system is also approaching a spatial limit.

Although the EROI for natural gas appears to be anomalously high, it has been suggested that the overall EROI (upstream and downstream) for natural gas may have been much higher than 100:1 in the past [31]. If true, then the EROI calculated here might be approximately correct because we only account for upstream energy costs. This seems to suggest that transmission and processing costs/losses could significantly affect both energy inputs and outputs. Even if transmission and processing costs lower EROI by $50 \%$ for any given year, the overall EROI for natural gas will still be appreciably higher than most other alternative fuels.

The EROI analyses presented here suggest that the concept of peak gas as defined by total production is misleading; energy requirements for natural gas extraction have a substantial impact on the total available gas. This is particularly troubling given the recent industry sponsored reports that are directed at convincing policy makers that there is abundant gas for the next several decades, even up to 100 years [5,36-38]. The conclusion of these reports is that more natural gas infrastructure is needed to improve economic stability and decrease our carbon output in the face of global warming. However, these pro-natural gas reports fail to account for the energy requirements and related changes in production characteristics. For example, imported liquid natural gas supplies come from other geologic locations with similar decline characteristics. This only avoids the inevitable supply depletion and at an added transportation cost. New shale gas reservoirs (i.e., unconventional gas) appear to have tremendous gas supply potential, however the depletion rate of individual wells and entire fields are much faster than conventional gas fields [39]. This means that shale gas may only provide a short-term extension to the total U.S. gas supply with a accelerated rate of depletion. Barnett Shale gas wells, which are at the heart of the much touted success story in natural gas development, currently reach the 
same production levels in a few years that the tight gas wells in the BVE play do in 16 years. As shale gas wells increasingly become dominant the overall decline rate of domestic production will accelerate, i.e., the summed depletion rate of individual gas wells must equal the overall depletion rate. Replacing slowly depleting wells with others that deplete faster, means that the total gas system will not deplete slowly over the next century. The large volumes of gas promised from shale reservoirs will likely maintain U.S. production at a reliable but modest level; however catastrophic drops in gas supply can be expected if shale gas is relied upon as a replacement of conventional gas. The implications of this analysis will likely hold true for crude oil, as it is a well-derived and finite resource with similar decline characteristics.

\section{Acknowledgements}

We thank Jon Freise, Carey King, and Arthur Berman for useful information, helpful discussion, and fruitful advice.

\section{References and Notes}

1. United States Department of Energy, Energy Information Agency. Natural gas data: http://www.eia.gov/naturalgas/data.cfm (accessed on 20 October 2011).

2. United States Department of Energy, Energy Information Agency. Energy Use in Manufacturing -1998 to 2002. Available on: http://www.eia.gov/ (accessed on 20 October 2011).

3. Lee, W. US lessons for energy industry restructuring: Based on natural gas and California electricity incidences. Energ. Policy 2004, 32, 237-259.

4. Bentley, R.W. Global oil \& gas depletion: An overview. Energ. Policy 2002, 30, 189-205.

5. The International Energy Agency World Energy Outlook 2009; OECD Publishing, Paris, France, 2009.

6. Hall, C.; Lindenberger, D.; Kümmel, R.; Kroeger, T.; Eichhorn, W. The need to reintegrate the natural sciences with economics. BioScience 2001, 51, 663-673.

7. Gagnon, N.; Hall, C.; Brinker, L. A preliminary investigation of energy return on energy investment for global oil and gas production. Energies 2009, 3, 490-503.

8. Almeda, P.; Silva, P.D. The peak of oil production-Timings and market recognition. Energ. Policy 2009, 37, 1267-1276.

9. Cheney, E.S.; Hawkes, M.W. The future of hydrocarbons: Hubbert's peak or a plateau? GSA Today 2007, 17, 69-70.

10. Reynolds, D.B.; Kolodziej, M. North American natural gas supply forecast: The Hubbert method including the effects of institutions. Energies 2009, 2, 269-306.

11. Deffeyes, K.S. Hubbert's Peak: The Impending World Oil Shortage; Princeton University Press: Princeton, NJ, USA, 2001.

12. Höök, M.; Söderbergh, B.; Jakobsson, K.; Aleklett, K. The evolution of giant oil field production behaviour. Nat. Resour. Res. 2009, 1, 39-56.

13. Höök, M.; Alekett, K. A decline rate study of Norwegian oil production. Energ. Policy 2008, 36, 4262-4271. 
14. Höök, M.; Hirsch, R.; Alekett, K. Giant oil field decline rates and their influence on world oil production. Energ. Policy 2009, 37, 2262-2272.

15. Söderbergh, B. Production from Giant gas fields in Norway and Russia and subsequent implications for European energy security. In Digital Comprehensive Summaries of Uppsala Dissertations from the Faculty of Science and Technology 705, 2010.

16. Interstate Oil and Gas Compact Commission (IOGCC) Marginal Wells: Fuel for Economic Growth; Oklahoma City, OK, USA, 2008.

17. Boswell, R.; Thomas, B.; Hussing, R.; Murin, T.; Donaldson, A. Upper Devonian Bradford sandstones and siltstones. In The Atlas of Major Appalachian Gas Plays; Roen, J., Walker, B., Eds.; West Virginia Geological and Economic Survey: Harrisburg, PA, USA, 1996; pp. 70-76.

18. Gross production data downloaded from the Pennsylvania Department of Conservation and Natural Resources. www.dcnr.state.pa.us/ (assessed on 12 October 2011) - Note: Production data for individual wells was acquired during several visits to the main offices of the Pennsylvania Department of Conservation and Natural Resources in Pittsburgh and Harrisburg, Pennsylvania.

19. Harper, J.; Tatlock, D.; Wolfe, R. Petroleum—Shallow oil and natural gas fields of Pennsylvania. In The Geology of Pennsylvania, Shultz, C., Ed.; Pennsylvania Bureau of Topographic and Geologic Survey: Harrisburg, PA, USA, 1999, Chapter 38-A, Fourth Series, Special Paper No. 1, pp. 485-505.

20. Kaiser, M. A survey of drilling cost and complexity estimation models. Int. J. Petrol. Sci. Technol. 2007, 1, 1-22.

21. Petroleum Services Association of Canada Well Costs Study. N.L. Fisher Supervision \& Engineering Ltd.: Calgary, Canada, 2005.

22. Stubbles, J.R. Energy Use in the U.S. Steel Industry Historical Perspective and Future Opportunities. Energetics, Inc.: Columbia, MD, USA, 2000.

23. Worrell, E.; Price, L.; Martin, N. Energy efficiency and carbon dioxide emissions reduction opportunities in the US iron and steel sector. Energy 2001, 26, 513-536.

24. Margolis, N.; Sousa, L. Energy and Environmental Profile of the U.S. Iron and Steel Industry, DOE/EE-0229; Energetics, Inc.: Columbia, MD, USA, 2000.

25. Pellegrino, J.; Margolis, N.; Justiniano, M.; Miller, M.; Thedki, A. Energy Use, Loss, and Opportunities Analysis for U.S. Manufacturing and Mining. Energetics, Inc. and EnergyEconomics Environment Modeling Laboratory: Columbia and North Potomac, MD, USA, 2004.

26. Worrell, E.; Galitsky, C. Energy Efficiency Improvement and Cost Saving Opportunities for Cement Making, An Energy Star Guide for Energy and Plant Managers; Energy Analysis Department, Environmental Energy Technologies Division, Ernest Orlando Lawrence Berkeley National Laboratory: Berkeley, CA, USA, 2004.

27. United States Department of Energy, Energy Information Agency Annual Energy Review, DOE/EIA-0384; 2008.

28. Yanoski, M., CEO of Target Energy, Inc., Indiana, PA, USA. Personal interview regarding Authorization for Expenditure reports, 2009.

29. Hall, C.; Balogh, S.; Murphy, J. What is the minimum EROI that a sustainable society must have? Energies 2009, 2, 25-47. 
30. Cleveland, C.; Costanza, R.; Hall, C.; Kaufmann, R. Energy and the U.S. economy: A biophysical perspective. Science 1984, 225, 890-897.

31. Cleveland, C. Net energy from the extraction of oil and gas in the United States. Energy 2005, 30, 769-782.

32. Gately, M. The EROI of U.S. offshore energy extraction: A net energy analysis of the Gulf of Mexico. Ecol. Econ. 2007, 63, 355-364.

33. Hayden, J.; Pursell, D. The Barnett Shale Visitors Guide to the Hottest Gas Play in the U.S. Pickering Energy Partners, Inc., Institutional Research: Houston, TX, USA, 2005.

34. Engelder, T. Marcellus 2008: Report card on the breakout year for gas production in the Appalachian Basin. Fort Worth Basin Oil Gas Mag. 2009, August, 19-22.

35. Hubbert, M.K. Nuclear energy and the fossil fuels: Drilling and production practice, Proc. Am. Petrol. Inst. Spring Meet. 1956, March, 7-25.

36. U.S. Natural Gas Availability: Gas Supply Through the Year 2000, OTA-E-245; Congress, Office of Technology Assessment: Washington, DC, USA, February 1985.

37. United States Department of Energy, Energy Information Agency Annual Energy Outlook, DOE/EIA-0383, 2010.

38. The Future of Natural Gas: An MIT Interdisciplinary Study-Interim Report, by the MIT Energy Initiative. Massachusetts Institute of Technology: Cambridge, MA, USA, 2010.

39. Berman, A. Shale Plays, Risk Analysis, and Other Perils of Conventional Thinking. Houston Geol. Soc. Bull. 2009, March, 27-35.

(C) 2011 by the authors; licensee MDPI, Basel, Switzerland. This article is an open access article distributed under the terms and conditions of the Creative Commons Attribution license (http://creativecommons.org/licenses/by/3.0/). 